\title{
Coupled Effect of Thickness Optimization and Plastic Forming History on Crashworthiness Performance of Thin-Walled Square Tube
}

Hasan Sofuoglu ( $\square$ sofuoglu@ktu.edu.tr)

Karadeniz Teknik Universitesi https://orcid.org/0000-0002-8433-4045

\section{Salim Çam}

Karadeniz Teknik Universitesi

\section{Research Article}

Keywords: Thin-walled square tube, Crashworthiness performance, Optimization, Plastic forming, Finite element analysis, Coupled effect

Posted Date: February 24th, 2021

DOI: https://doi.org/10.21203/rs.3.rs-231138/v1

License: (c) (i) This work is licensed under a Creative Commons Attribution 4.0 International License. Read Full License

Version of Record: A version of this preprint was published at The International Journal of Advanced Manufacturing Technology on August 19th, 2021. See the published version at https://doi.org/10.1007/s00170-021-07865-y. 


\section{Abstract}

Thin-walled tubes are widely used as energy absorbers due to their high crashworthiness performance. This study aims to evaluate the effect of plastic forming history carried out for thickness optimization on crashworthiness performance of thin-walled square tube (TWST). Within the scope of the study, a series of numerical analyses were conducted for the TWST using a commercial finite element (FE) software. In order to determine individual effect of optimization, FG thickness of TWST was first obtained using LSOPT software. Later, thickness gradient was achieved by performing rolling process to consider individual plastic forming effect Afterwards, deep drawing process was carried out to shape TWST by considering springback and trimming effects. Finally, crash responses were obtained under axial high velocity impact loading to determine the coupled effect of optimization and plastic forming on the crashworthiness performance of the TWST. It was determined that the coupled effect, which takes plastic forming and optimization effects into account, reduced the peak crush force of the TWST by $24 \%$ and increased the absorbed energy value by $39 \%$. The results obtained from this study showed that coupled effect of optimization and plastic forming processes has significant effect on the crashworthiness performance of the TWST and otherwise either overestimated or underestimated results are obtained.

\section{Introduction}

Thin-walled structures have been used as energy absorbers for a long time and have attracted many researchers. Since then, an enormous amount of contribution has been made to the related field. Effect of tube geometry [1-4], material type [5, 6], filling materials [7-9] widely investigated by researchers. Moreover, advances in the manufacturing processes and a growing interest in engineering optimization allowed researchers to study more complex geometries $[10,11]$. Thin-walled tubes with functionally graded (FG) thickness created to improve energy absorption efficiency and crush resistance performance are the product of these developments $[12,13]$.

Li et al. [14] compared different FG thickness on the crashworthiness of thin-wall tubes under multiple loading angles. They optimized the thin-walled tube using NSGA-II algorithm and concluded that graded thickness reduces the possibility of global bending. Zhang and Zhang [15] investigated effect of nonlinear thickness distribution considering conical tubes. They implemented tapering process to FE analyses in order to obtain nonlinear thickness distribution. The results showed that the energy absorption capacity of the tubes increased by $120 \%$. Sun et al. [16] studied effect of thickness gradient under axial impact load. They used a gradient exponent parameter to control thickness gradient and optimized thickness distribution. They stated that exponent parameter has considerable effect on the crashworthiness.

Another aspect related to the complex geometries is the effect of the manufacturing processes on the crash response. Lee et al. [17] performed crash simulations for side rail and hydro-formed tube considering forming history. They stated that forming history of components affects crash response concidarahlv Alen thav ammhacizod that tho weo of noarger mesh yields equally good results when Loading [MathJax]/jax/output/CommonHTML/fonts/TeX/fontdata.js 
compared to finer mesh. Gao et al. [18]compared the crash responses for one-step forming and incremental forming. They explained that there is a considerable difference between two methods and concluded that incremental forming simulation provides more accurate results. Kumar and Shrivaathsav [19] investigated influence of forming parameters for capped cylindrical tubes. They stated that thickness variation and residual stress/strains originated from forming application improves impact performance of the tubes compared to tubes with constant thickness. Du et al. [20] proposed an inverse method for implementing stamping effect to the crash simulations. Considering side rail, they indicated that with regards to the simulation accuracy effective plastic strain is more important than thickness reduction. Niu et al. [21] compared the effect of the stamping and bending on crash performance. They observed progressive buckling for bent specimens and global instability for stamped specimens. Karagöz and Yıldız [22] optimized tube geometry using various optimization algorithms considering forming effects. They stated that forming process has considerable effect on the crash performance of the tubes. Doruk [23] investigated effect of steel processing effects on the crash performance of the automobile frontal bumper system. Bumper beam and energy absorbers produced considering effect of deep drawing, trimming and springback. The results obtained showed that with counting effect of forming history, parts of bumper system absorbed $12.89 \%$ more energy. Effect of deep drawing for quasi-static axial crash was also studied by Gümrük and Karadeniz [24]. They concluded that whereas plastic strain and thinning affect the crash response, residual stress has limited effects.

Considering studies summarized above and many more published in the related field of the literature, it is obvious that FG thickness improves crash performances of the tubes. It is also clear form these studies that plastic forming methods affect crash performances of the tubes considerably. However, to the best of authors' knowledge, the coupled effect of thickness optimization and the plastic forming method used to obtain thickness gradient has not taken any attention and studied until now. This study was therefore carried out to investigate the effects of plastic forming history pursued for thickness optimization on crashworthiness performance of the TWST, namely the coupled effect of optimization and plastic forming.

\section{Materials And Methods}

This study consists of four stages; FG thickness optimization, rolling, deep drawing, and crush analysis. In order to perform these stages, a series of FE analyses conducted using commercial FE software, LSDYNA. In the first phase of this study, the thickness of TWST was optimized using LS-OPT software to obtain the comparison results to be used in determining the coupled effect of optimization and plastic forming. Rolling process was then conducted to achieve the intended thickness gradient on the plate rather than directly importing optimized thickness values to the FE model. Later, deep drawing was applied to the plate having the desired thickness gradient after rolling to shape the thin-walled square tube. Finally, crush analysis under high velocity impact load was carried out to determine the coupled effect of optimization and plastic forming on the crashworthiness performance of the TWST. 
In this study, mild steel ( $E=207 \mathrm{GPa}, \mathrm{v}=0.3)$ was used for energy absorber material [2]. The stress-strain values given as tabular data in reference 2 were arranged and given graphically in Fig. 1 . Because of its strain rate sensitivity and suitability of crash modeling [3-5,25], piecewise linear plasticity was selected for material model. Effect of the strain rate was implemented by activating VP (Formulation for rate effects) option which uses Cowper-Symonds constitutive model. Cowper-Symonds equation is expressed by scaling two factors; strain and strain rate factors [26];

$$
\sigma_{y}=\left[1+\left(\frac{\dot{\varepsilon}}{c}\right)^{\frac{1}{p}}\left(\sigma_{0}+\beta E_{p} \varepsilon_{p}^{\text {eff }}\right)\right]
$$

where $\sigma_{0}$ is the initial yield stress, $\dot{\varepsilon}$ is the strain rate, $C$ and $P$ are strain rate parameters. Also $\beta$ represents the strain hardening parameter, $\varepsilon_{p}^{\text {eff }}$ is the effective plastic strain and $E_{p}$ is the plastic hardening modulus. A computational method was then proposed to determine the Cowper-Symonds parameters from a single Taylor test [27]. Later on, the following form of the equation was used to implement strain rate effects into FEA [28]:

$$
1+\left(\frac{\dot{s}}{c}\right)^{1 / p}
$$

Within the scope of the study the strain rate parameters $C$ and $P$ are selected as $6.844(\mathrm{~ms})^{-1}$ and 3.91, respectively [29].

Figure 2 illustrates the base FE model for TWST. The base model of the TWST has a constant thickness of $1.5 \mathrm{~mm}$ and, it corresponds to a mass of $1 \mathrm{~kg}$. The tube geometry was partitioned into 12 pieces to perform thickness optimization. The side length of the tube is $90 \mathrm{~mm}$, while $240 \mathrm{~mm}$ is the total length. The TWST was meshed using a $5 \times 5 \mathrm{~mm}$ Belytschko-Tsay shell element with five integration points through the thickness. The TWST is fixed from bottom and a solid-rigid wall with $100 \mathrm{~kg}$ mass impacts the tube with a speed of $54 \mathrm{~km} / \mathrm{h}$. For the contacts between lobes of the TWST and between the TWST and the rigid wall, automatic single surface contact algorithm was used. A constant friction coefficient of 0.2 was applied to all contacts surfaces. Also, hourglass was controlled via control hourglass card.

\subsection{Validation of the finite element model}

Before proceeding with the actual analysis, it should be shown that the FE model created for the problem simulation is correct. Two finite element analyses (FEA), namely mesh convergence and model validation studies, were conducted within this purpose. Three different element sizes of $1.25,2.5$, and $5 \mathrm{~mm}$ were evaluated in order to assess the effect of element size. Figure 3 shows the results of the mesh convergence studies. For each element size, crush force - crush displacement curves showed a good 
(PCF) are nearly identical. Similarly, the absorbed energy versus crush displacement plots initially follow almost the same path, although there is a deviation towards the end of the process, the difference is negligible. It has been shown that the FE model is not affected by the element sizes tested in this study. Also, for validation purposes, the FE model in the Nagel and Thambiratnam's study [2] reproduced and the results were compared. While the results were in perfect harmony for the peak force at the beginning of the process, as seen in Fig. 4, this consistency decreased at the end showing little fluctuations. After the convergence and verification studies, it was concluded that the FE model created could be used in the studies that constitute future stages of this research.

Prior to thickness optimization, the FEA of TWST was performed with a constant thickness of $1.5 \mathrm{~mm}$ for subsequent comparison studies (will be named as single-piece tube). As can be seen from the Fig. 5 that the preliminary results for the TWST with constant thickness were obtained to be $240 \mathrm{kN}$ and $9.9 \mathrm{~kJ}$ for the PCF and the absorbed energy, respectively

\subsection{Effect of thickness optimization}

After carrying out the FEA of TWST with constant thickness, thickness optimization of the TWST was performed using LS-OPT software. For each section of the tube, a thickness parameter; a total of 12 parameters were defined and the mass of the tube, absorbed energy, and peak crushing force was calculated. LS-OPT offers six different metamodeling techniques namely; Polynomial, Sensitivity, Feed Forward Neural Network (FNN), Radial Basis Function Network (RBFN) and Kriging. However, when using polynomial-based response surfaces, the user has to choose the order of polynomial and there is a considerable possibility of bias error [30]. Meanwhile, Kriging has fitting problems [31] and considerably sensitive to noise [32]. Distinctly, RBFN and FNN have not serious deficiencies and they are similar in terms of accuracy. Moreover it is known that FNN is better than RBFN for some problems [33]. In this study, thickness values were therefore determined by the FNN method to maximize absorbed energy and 1/PCF values. For each thickness, 20 simulation points with a space-filling scheme were selected. Also, with regards to the result obtained from the TWST with constant thickness, the mass of the tube was constrained by $1 \mathrm{~kg}$ while the peak crush force between $0-5 \mathrm{~ms}$ was constrained by $240 \mathrm{kN}$. Figure 6 shows the flowchart of the optimization process. Figure 6 shows the flowchart of the optimization process while the scatter plot of the simulation results is illustrated in Fig. 7.

Optimum thickness values of the TWST obtained from multi-objective optimization are given in Table 1 while Fig. 8 shows the crush responses obtained from the FEA of the optimized model. The optimized model showed a significant improvement in terms of both peak crush force (PCF) and absorbed energy. While the PCF was obtained as $150 \mathrm{kN}$ with a $37.5 \%$ decrease, the amount of absorbed energy increased by $18 \%$ to $11.68 \mathrm{~kJ}$. However, after $100 \mathrm{~mm}$ of deformation, the crush force of the optimized TWST starts to increase and exceeds the crush force of the TWST with constant thickness after $130 \mathrm{~mm}$. This is inevitable behavior due to the nature of the TWST with graded thickness. If the thickness of the tube is constant, the crash force shows only small peaks afterward of deformation initiation. However, for the case of optimized tube, deformation initiates from the thinner section of the tube (t2-t7) and the crush 
force does not make another considerable peak until the thinner section completely deforms. With the increased thickness sections of the TWST (t8-t12), there is more force needed to initiate new deformation.

Table 1

Thickness values of the FG-TWST obtained from multiobjective optimization

\begin{tabular}{|lllllll|}
\hline \multicolumn{7}{|c|}{ Optimum Thickness Values (mm) } \\
\hline$t_{1}$ & $t_{2}-t_{7}$ & $t_{8}$ & $t_{9}$ & $t_{10}$ & $t_{11}$ & $t_{12}$ \\
\hline 2.26 & 0.96 & 1.13 & 1.73 & 1.78 & 2.41 & 2.29 \\
\hline
\end{tabular}

\subsection{Effect of plastic forming}

Apparently, there is quite an improvement in the crashworthiness performance of the TWST in optimization process needed to achieve such a graded thickness. However, the results given above and in most of the literature have been obtained without considering the effects of the manufacturing processes used in the optimization method. Therefore, the validity of the results obtained in this way for the crashworthiness performance of the TWST can be questionable.

The most convenient and economical manufacturing process to achieve graded thickness is rolling. However, it is not possible to produce the TWST as a whole with rolling process only. For this reason, after achieving variable thickness via rolling, the tube geometry was produced in two parts by deep drawing process. As a result, rolling and deep drawing processes were sequentially performed in order to investigate the coupled effect of optimization and plastic forming on the TWST's crashworthiness performance in this study. Subsequently these two parts was welded to form the square tube for crush analysis. Each forming analysis connected to each other via dynain file until crush analysis of the tube.

\subsubsection{Rolling}

The FE model of the rolling was constructed in two dimensional. Both rolls and workpiece were meshed using plane strain elements. In order to reduce complexity it was assumed that workpiece kept constant while movement was applied to rolls modelled as rigid. For the contacts between rolls and the workpiece $2 D$ automatic surface to surface contact algorithm was used. The friction coefficient between the rolls and the workpiece was considered to be zero in order to simulate rotating effect.

The thickness of the plate was initially $2.5 \mathrm{~mm}$. Considering thickness values obtained from multiobjective optimization the workpiece was partitioned into 12 sections. The length of each section was determined with regard to the conservation of volume. Maximum thickness reduction was limited to $40 \%$ for a single pass and multiple passes applied to the sections to obtain required thickness. To control thickness reduction, contact between the rolls and the workpiece was only activated for the related section of the workpiece. Table 2 shows thickness distribution of the sheet after rolling process. 
Table 2

Thickness distribution of the workpiece after rolling process

\begin{tabular}{|lllllll|}
\hline \multicolumn{7}{|c|}{ Thickness Values $( \pm 0.02 \mathrm{~mm})$} \\
\hline $\mathrm{t}_{1}$ & $\mathrm{t}_{2}-\mathrm{t}_{7}$ & $\mathrm{t}_{8}$ & $\mathrm{t}_{9}$ & $\mathrm{t}_{10}$ & $\mathrm{t}_{11}$ & $\mathrm{t}_{12}$ \\
\hline 2.28 & 0.98 & 1.14 & 1.74 & 1.78 & 2.40 & 2.32 \\
\hline
\end{tabular}

\subsubsection{Deep drawing}

Deep drawing process was used to produce a half of the TWST from the plate with graded thickness. The finite element model of the deep drawing consists of four parts: Workpiece, punch, die and binders. Schematic illustration of deep drawing process is given in Fig. 9.

In deep drawing process, a trapezoidal punch velocity profile with maximum speed of $2 \mathrm{~mm} / \mathrm{ms}$ was used as given in Fig. 10. Tool motion defined with the boundary prescribed motion rigid keyword.

All parts were meshed with Belytschko-Tsay shell element and 5 integration points through the thickness of workpiece was utilized. Using control shell keyword, shell element thickness change and warping stiffness were activated. A stiffness type of hourglass control implemented to the FE model with control hourglass keyword. The punch, the die and binders were modelled as rigid while for workpiece piecewise linear plasticity material model was used. Contacts between the workpiece and other parts created using forming one way surface to surface contact algorithm with friction coefficient of 0.1 . Shell thickness offsets were activated with control contact keyword excluding rigid bodies. The workpiece meshed with $5 \times 5 \mathrm{~mm}$ elements and adaptive mesh refinement activated by adpopt flag in the part keyword. Finally, springback analysis was established using interface springback seamless keyword. Figure 11 shows the effective plastic strain values of the workpiece obtained from the springback analysis.

After springback analysis surplus sections of the workpiece was trimmed using element trim keyword and the final form of the workpiece is given in Fig. 12.

\subsection{Crush Analysis with coupled effect}

Prior to this section thickness gradient of the TWST was achieved by performing rolling process while deep drawing process was then used to form the tube geometry. In this section, crash analysis was then carried out by considering the coupled effects of optimization and plastic forming carried out for thickness optimization. After rolling and deep drawing processes, configuration of tube has minor changes due to nature of the forming processes, e.g., the corners of the tube are smooth due to deep drawing process. After deep drawing process, there are now two symmetric half-tubular parts with graded thickness to build up TWST. These two symmetric parts were then connected to each other using 22 spot welds. Spot welds were modelled using constrained spot weld keyword and considered as rigid. Failure of 
model given above. The thickness distribution and the residual plastic strains of the tube prior to crush analysis were given in Fig. 13.

Although the geometry of the built up TWST, named as two-piece tube, did not change significantly compared to single-piece TWST, FE analyzes were rerun to determine individual effects of plastic forming and optimization. Figure 14 shows only the plastic forming effect on crashworthiness performance of the TWST by comparing the single-piece and two-piece tubes with constant thickness. The values of PCF and total absorbed energy dropped from $240 \mathrm{kN}$ to $215 \mathrm{kN}$ and from $9.9 \mathrm{~kJ}$ to $9.5 \mathrm{~kJ}$ by showing $9 \%$ and $4 \%$ decrease from a single-piece tube to two-piece tube, respectively. In addition to this, the results showing only the optimization effect in one-piece and two-piece tubes with graded thickness were given in Fig. 15. The PCF decreased from $150 \mathrm{kN}$ to $139 \mathrm{kN}$ while the total amount of absorbed energy also dropped from $11.68 \mathrm{~kJ}$ to $10.4 \mathrm{~kJ}$ from the single-piece tube to the two-piece tube, respectively. The decrease in the PCF and the absorbed energy corresponds to $7 \%$ and $11 \%$, respectively. As mentioned above, all these results are just individual effects and independent of the coupled effect of optimization and plastic forming.

The final stage of this study has therefore been carried out by using two-piece tube to assess the coupled effect of optimization and plastic forming history on the TWST with graded thickness. More precisely, Fig. 16 shows the coupled effect on the crashworthiness performance of two-piece tube rolled to obtain optimized thickness. It is very clear from the figure that considering only the optimization effect, the obtained PCF and the absorbed energy were $139 \mathrm{kN}$ and $10.4 \mathrm{~kJ}$, respectively. After the coupled effect, which took the plastic forming effect into account, the PCF increased by $18 \%$ to $164 \mathrm{kN}$ while the absorbed energy increased by $27 \%$ to $13.2 \mathrm{~kJ}$. On other hand, these results correspond to $24 \%$ decrease in the PCF from $215 \mathrm{kN}$ to $164 \mathrm{kN}$ and $39 \%$ increase from $9.5 \mathrm{~kJ}$ to $13.2 \mathrm{~kJ}$ in total absorbed energy compared to the two-piece tube with constant thickness as shown in Fig. 17. Moreover, after the optimization process of the two-piece tube, the PCF decreased by $35 \%$ ( $215 \mathrm{kN}$ to $139 \mathrm{kN})$ and the amount of absorbed energy increased by $9 \%$ ( $9.5 \mathrm{~kJ}$ to $10.4 \mathrm{~kJ})$. As clearly seen from Fig. 17 that the results of this study showed that plastic forming history, when evaluated together with thickness optimization, has significant effects on the crashworthiness performance of the TWST.

\section{Conclusion}

In this study the combined processes of rolling and deep drawing was investigated via FE method since more than one manufacturing process is needed to achieve graded thickness geometry in energy absorbing thin walled tube. The thickness gradient of the TWST was achieved by rolling while deep drawing process was performed to obtain the square tube form. Thus, the coupled effect of optimization and plastic forming on the crashworthiness performance of the TWST was studied. On the other hand, FG thickness of the TWST was obtained using LS-OPT software with FNN method to determine the individual effect of optimization and to compare the results with those of the coupled effect.

This study showed that the coupled effect of optimization and plastic forming has the significant effect on tho rrachworthinoce norformanno of tho TW/CT It wac also determined that considering optimization Loading [MathJax]/jax/output/CommonHTML/fonts/TeX/fontdata.js 
and plastic forming effects individually resulted in either overestimated or underestimated findings. Moreover, it is certain that neglecting the coupled effect that leads to considerable differences in the crashworthiness performance of the TWST will have negative consequences in industries where manufacturing is made using the similar, such as automotive industry. Therefore, it should be noted that both the thickness optimization obtained without considering the plastic forming effect and the plastic forming effect obtained without considering the thickness optimization should not be used to evaluate the crashworthiness performance of the energy absorber tubes.

\section{References}

1. Abramowicz W, Jones $N$ (1986) Dynamic progressive buckling of circular and square tubes. Int $J$ Impact Eng 4:243-270. doi:10.1016/0734-743X(86)90017-5

2. Nagel GM, Thambiratnam DP (2004) A numerical study on the impact response and energy absorption of tapered thin-walled tubes. Int J Mech Sci 46:201-216. doi:10.1016/j.jimecsci.2004.03.006

3. Reddy S, Abbasi M, Fard M (2015) Multi-cornered thin-walled sheet metal members for enhanced crashworthiness and occupant protection. Thin-Walled Struct 94:56-66. doi:10.1016/j.tws.2015.03.029

4. Tran TN (2017) Crushing analysis under multiple impact loading cases for multi-cell triangular tubes. Thin-Walled Struct 113:262-272. doi:10.1016/j.tws.2017.01.013

5. Smerd R, Winkler S, Salisbury C, Worswick M, Lloyd D, Finn M (2005) High strain rate tensile testing of automotive aluminum alloy sheet. Int $\mathrm{J}$ Impact Eng 32:541-560. doi:10.1016/j.jimpeng.2005.04.013

6. Itabashi M, Kawata K (2000) Carbon content effect on high-strain-rate tensile properties for carbon steels. Int J Impact Eng 24:117-131. doi:10.1016/S0734-743X(99)00050-0

7. Gedikli $H$, Meriç D, Energy absorption behavior of tailor-welded tapered tubes under axial impact loading using coupled FEM/SPH method, Thin-Walled 104 (2016). doi:10.1016/j.tws.2016.03.002

8. Coelho RM, Alves de Sousa RJ, Fernandes FAO, Teixeira-Dias F (2013) New composite liners for energy absorption purposes. Mater Des 43:384-392. doi:10.1016/j.matdes.2012.07.020

9. Ahmad Z, Thambiratnam DP (2009) Dynamic computer simulation and energy absorption of foamfilled conical tubes under axial impact loading. Comput Struct 87:186-197. doi:10.1016/j.compstruc.2008.10.003

10. Costas M, Díaz J, Romera L, Hernández S (2014) A multi-objective surrogate-based optimization of the crashworthiness of a hybrid impact absorber. Int J Mech Sci 88:46-54. doi:10.1016/j.ijmecsci.2014.07.002

11. Gedikli H (2013) Crashworthiness optimization of foam-filled tailor-welded tube using coupled finite element and smooth particle hydrodynamics method. Thin-Walled Struct 67:34-48. doi:10.1016/i.tws.2013.01.020 
12. Zhang X, Zhang H, Wen Z (2015) Axial crushing of tapered circular tubes with graded thickness. Int J Mech Sci 92:12-23. doi:10.1016/j.ijmecsci.2014.11.022

13. Zhang $X$, Wen Z, Zhang $H$ (2014) Axial crushing and optimal design of square tubes with graded thickness. Thin-Walled Struct 84:263-274. doi:10.1016/j.tws.2014.07.004

14. Li G, Zhang Z, Sun G, Huang X, Li Q (2015) Comparison of functionally-graded structures under multiple loading angles. Thin-Walled Struct 94:334-347. doi:10.1016/j.tws.2015.04.030

15. Zhang $H$, Zhang $X$ (2016) Crashworthiness performance of conical tubes with nonlinear thickness distribution. Thin-Walled Struct 99:35-44. doi:10.1016/j.tws.2015.11.007

16. Sun G, Xu F, Li G, Li Q (2014) Crashing analysis and multiobjective optimization for thin-walled structures with functionally graded thickness. Int J Impact Eng 64:62-74. doi:10.1016/j.jimpeng.2013.10.004

17. Lee $\mathrm{SH}$, Han CS, Oh SI, Wriggers $P$ (2001) Comparative crash simulations incorporating the results of sheet forming analyses. Eng Comput (Swansea Wales) 18:744-758. doi:10.1108/EUM0000000005786

18. Gao R, Xi C, Tyan T, Mahadevan K, Doong J (2009) A practical approach to consider forming effects for full vehicle crash application. SAE Tech Pap. doi:10.4271/2009-01-0471

19. Praveen Kumar A, Shrivaathsav S (2019) Influence of forming parameters on the crash performance of capped cylindrical tubes using LS-DYNA follow-on simulations. Int J Interact Des Manuf 13:12151232. doi:10.1007/s12008-019-00552-z

20. Du H, Ye P, Wang D, Tang $X$, Study on accuracy improvement of vehicle crash simulation considering stamping effects, Adv Mater Res 139-141 (2010) 532-535.

doi:10.4028/www.scientific.net/AMR.139-141.532

21. Niu J, Zhu P, Guo Y, Crush performance of top-hat tubular structures considering different forming conditions, Adv Mater Res 139-141 (2010) 571-575. doi:10.4028/www.scientific.net/AMR.139141.571

22. Karagöz S, Yildiz AR (2017) A comparison of recent metaheuristic algorithms for crashworthiness optimisation of vehicle thin-walled tubes considering sheet metal forming effects. Int J Veh Des 73:179-188. doi:10.1504/IJVD.2017.082593

23. Doruk E (2017) Steel processing effects on crash performance of vehicle safety related applications. Steel Compos Struct 24:351-358. doi:10.12989/scs.2017.24.3.351

24. Gümrük R, Karadeniz S (2009) The influences of the residual forming data on the quasi-static axial crash response of a top-hat section. Int J Mech Sci 51:350-362. doi:10.1016/j.ijmecsci.2009.03.010

25. Zhang X, Zhang H, Ren W (2018) Axial crushing of tubes fabricated by metal sheet bending. ThinWalled Struct 122:252-263. doi:10.1016/j.tws.2017.09.023

26. Cowper GR, Symonds PS, Strain hardening and strain-rate effects in the impact loading of cantilever beams, 1957 
27. Hernandez C, Maranon A, Ashcroft IA, Casas-Rodriguez JP (2013) A computational determination of the Cowper-Symonds parameters from a single Taylor test. Appl Math Model 37:4698-4708. doi:10.1016/j.apm.2012.10.010

28. LS-DYNA Keyword User's Manual Volume II: Material Models, Livermore Software Technology Corporation, California, 2018

29. Guler MA, Cerit ME, Bayram B, Gerçeker B, Karakaya E (2010) The effect of geometrical parameters on the energy absorption characteristics of thin-walled structures under axial impact loading. Int $\mathrm{J}$ Crashworthiness 15:377-390. doi:10.1080/13588260903488750

30. Stander N, Roux W, Basudhar A, Eggleston T, Goel T, Craig K (2015) LS-OPT User 's Manual: A Design Optimization and Probabilistic Analysis Tool for The Engineering Analyst. Livermore Software Technology Corporation, California

31. Xu QS, Liang YZ, Fang KT (2000) The effects of different experimental designs on parameter estimation in the kinetics of a reversible chemical reaction. Chemom Intell Lab Syst 52:155-166. doi:10.1016/S0169-7439(00)00084-8

32. Jin R, Chen W, Simpson TW (2001) Comparative studies of metamodelling techniques under multiple modelling criteria. Struct Multidiscip Optim 23:1-13. doi:10.1007/s00158-001-0160-4

33. Stander N, Goel T, Metamodel sensitivity to sequential adaptive sampling in crashworthiness design, içinde: 12th AIAA/ISSMO Multidiscip. Anal. Optim. Conf., 2008

\section{Figures}

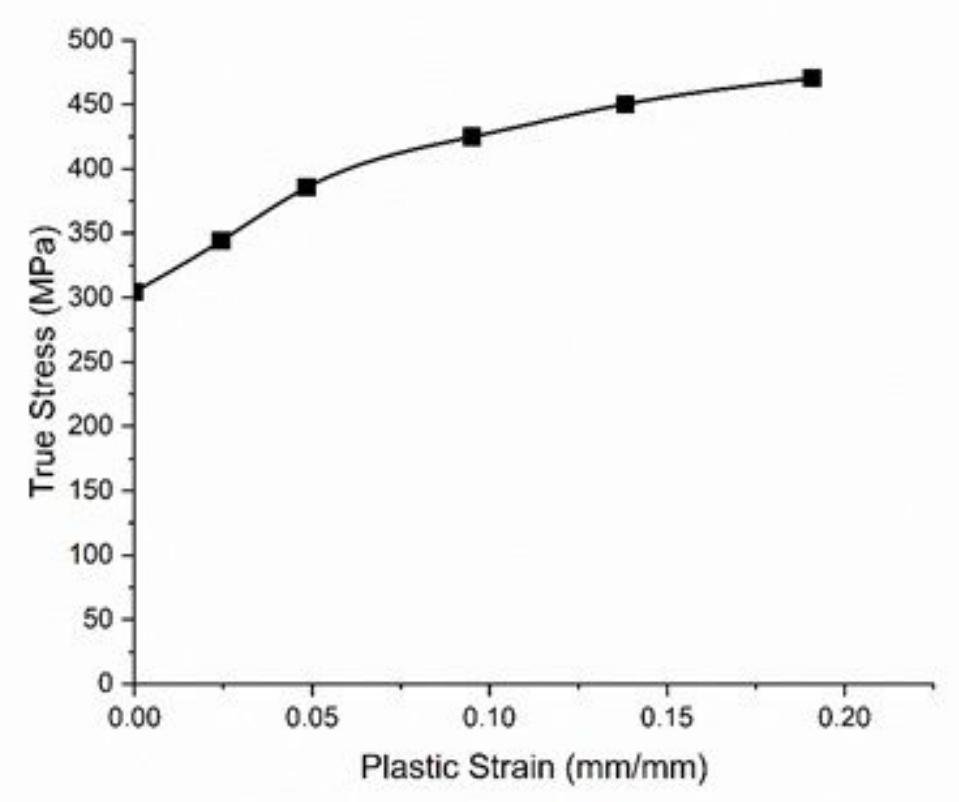

\section{Figure 1}




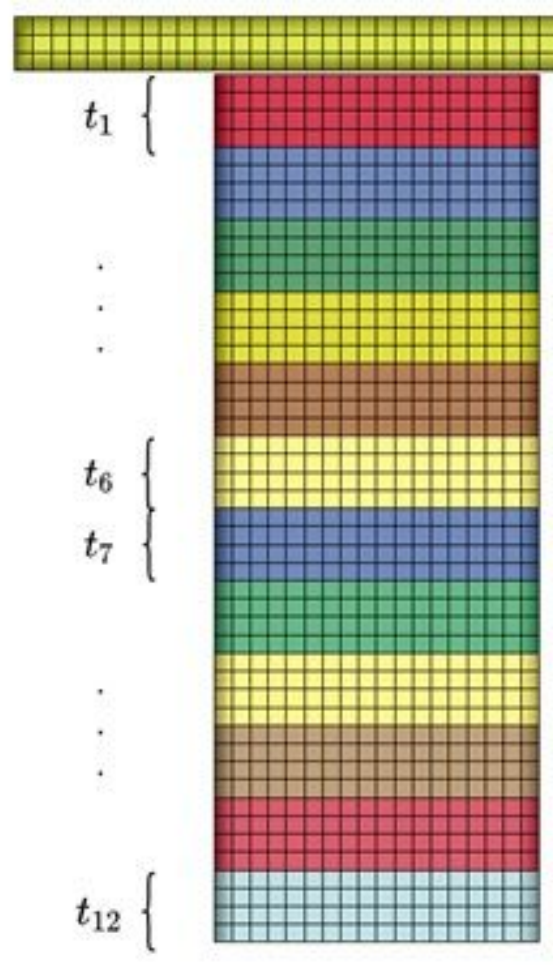

Figure 2

FE Model of the TWST
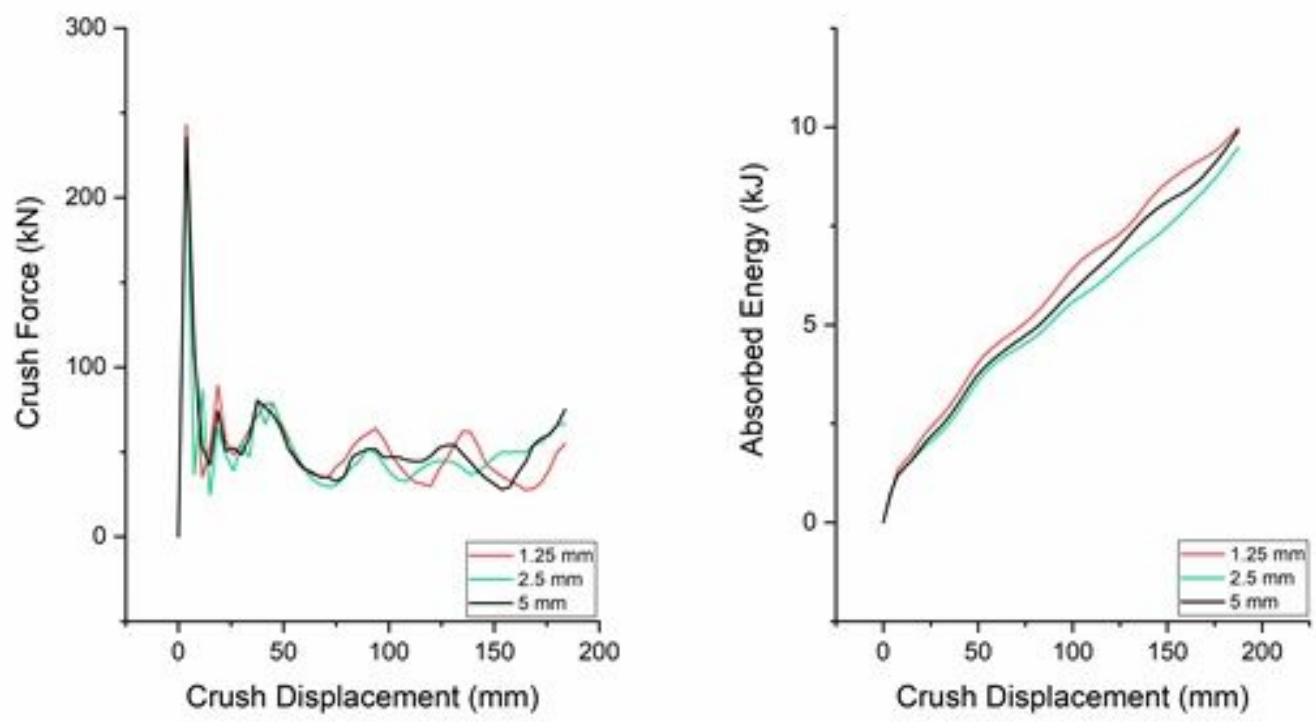

Figure 3

Mesh convergence study 


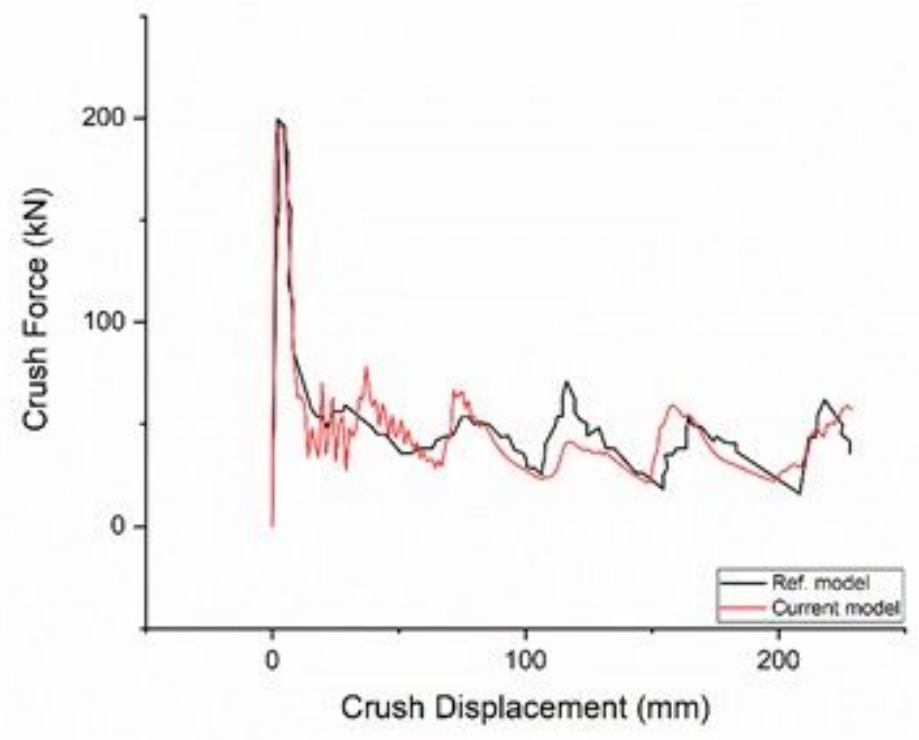

\section{Figure 4}

Validation study of the FE model
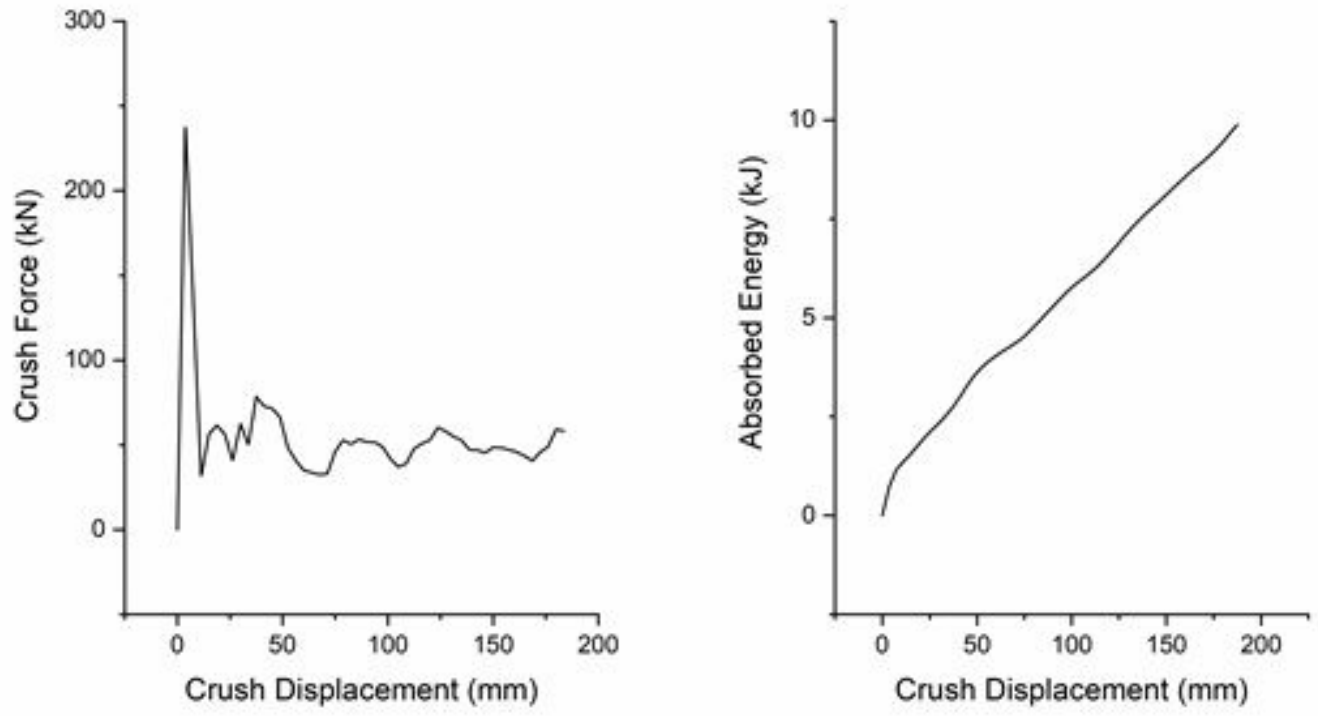

Figure 5

Crashworthiness performance of the TWST with constant thickness of $1.5 \mathrm{~mm}$ 


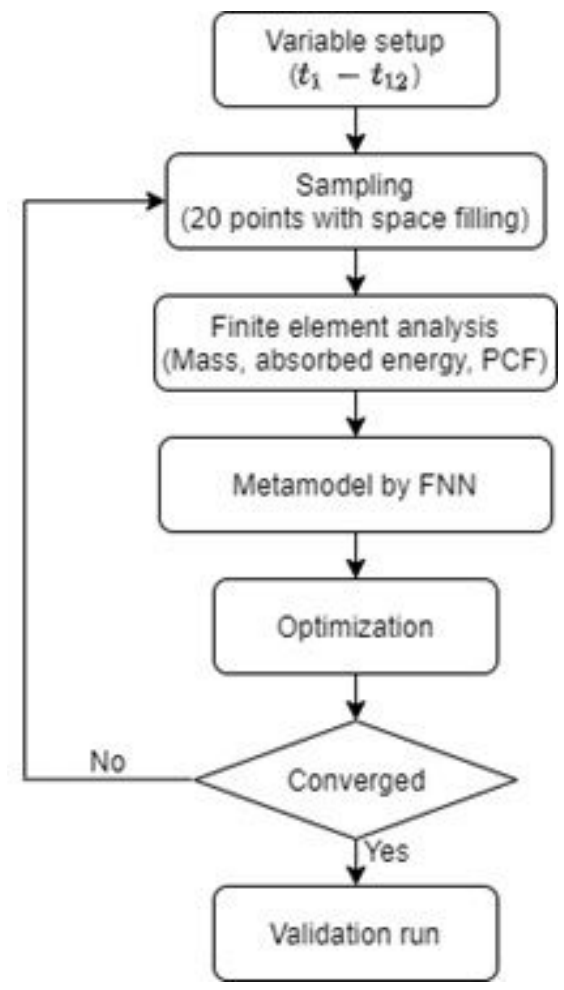

Figure 6

Flowchart of the optimization process

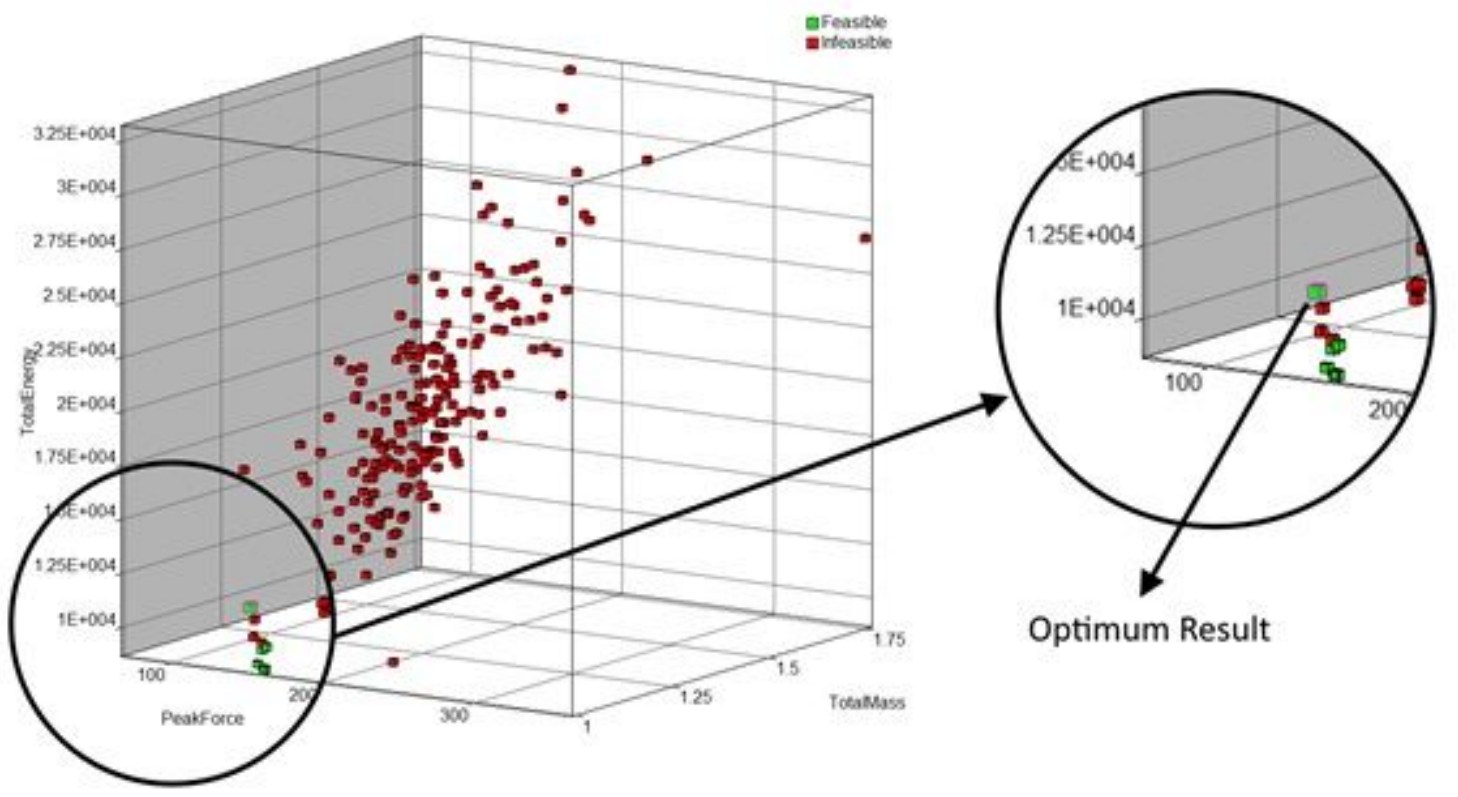

Figure 7

Scatter plot for optimization process 

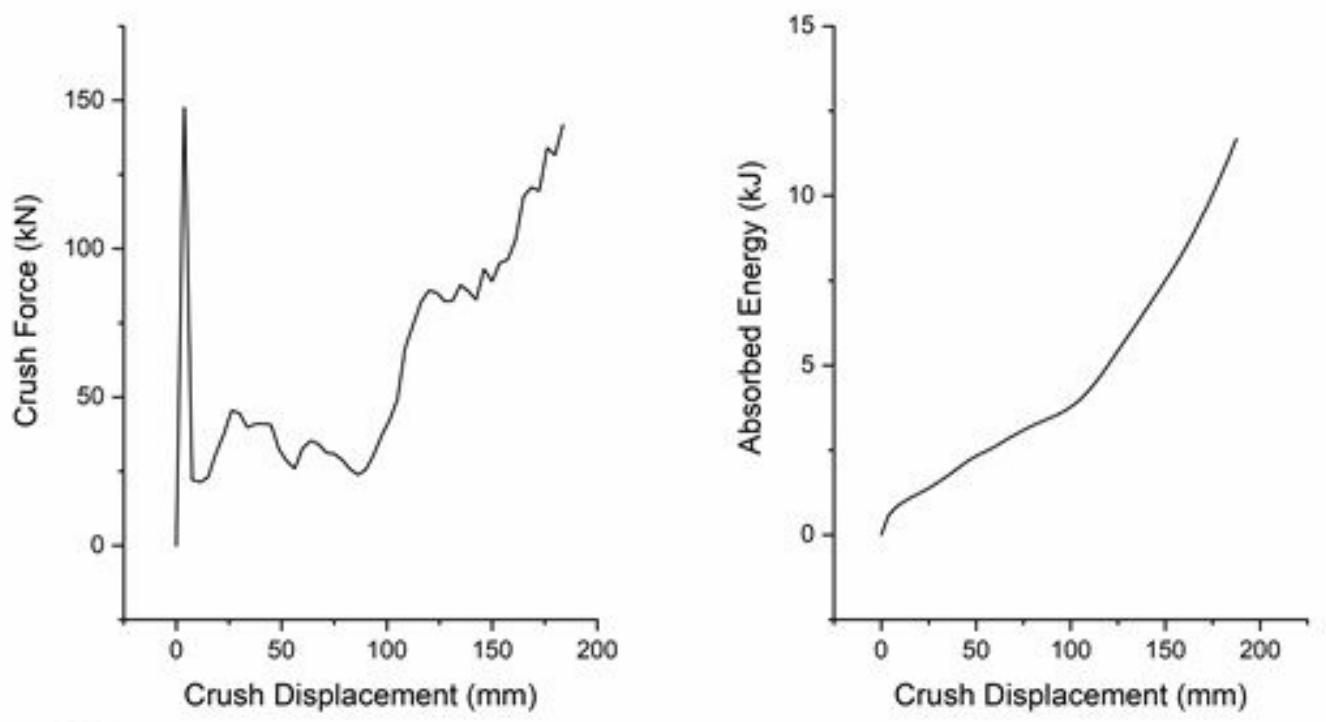

\section{Figure 8}

Optimization effect on the crashworthiness performance of the FG-TWST
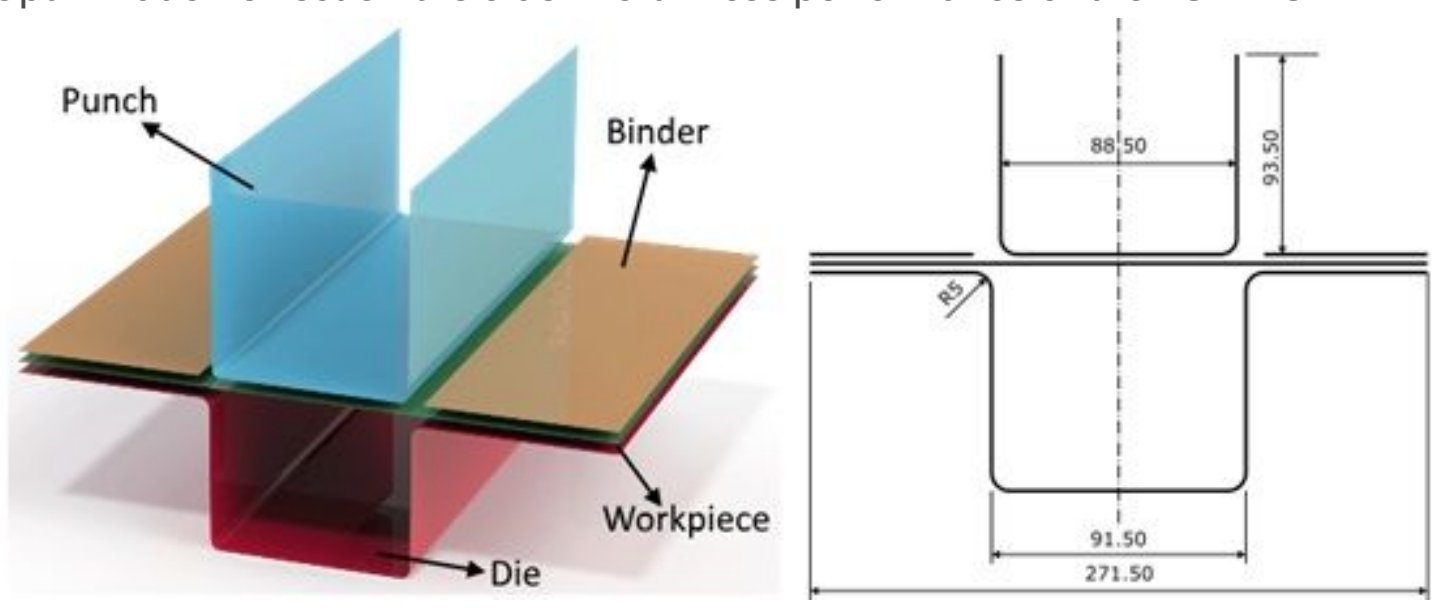

Figure 9

Schematic illustration of deep drawing process 


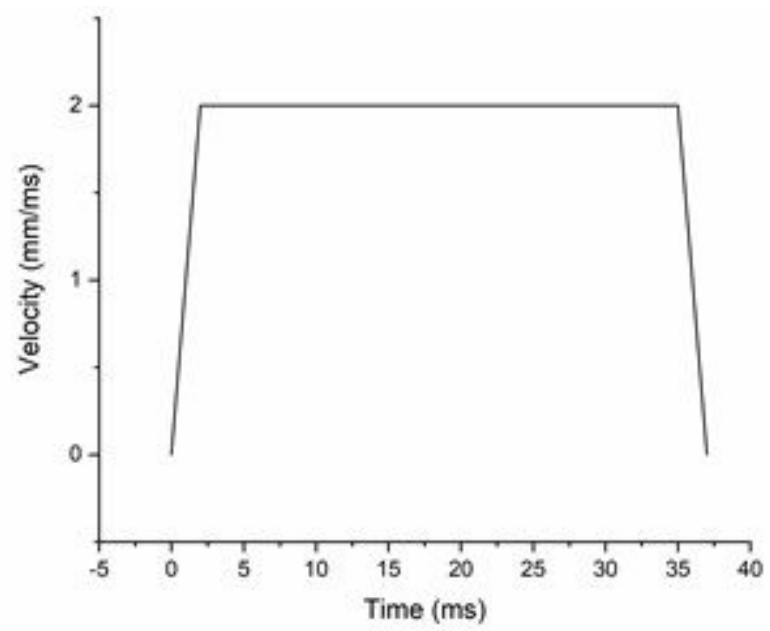

Figure 10

Punch velocity curve

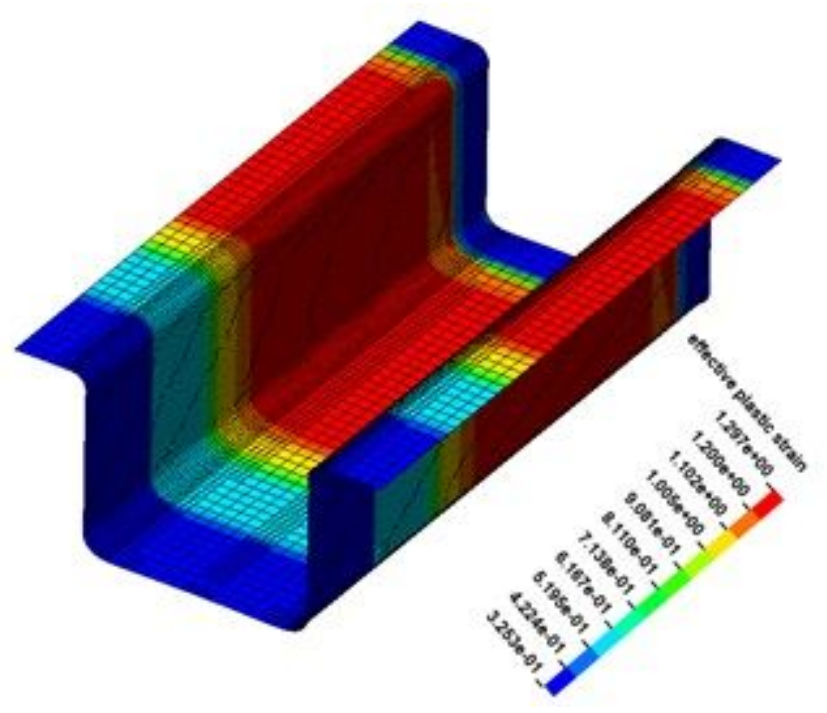

Figure 11

Effective plastic strain distribution of the workpiece after deep drawing 


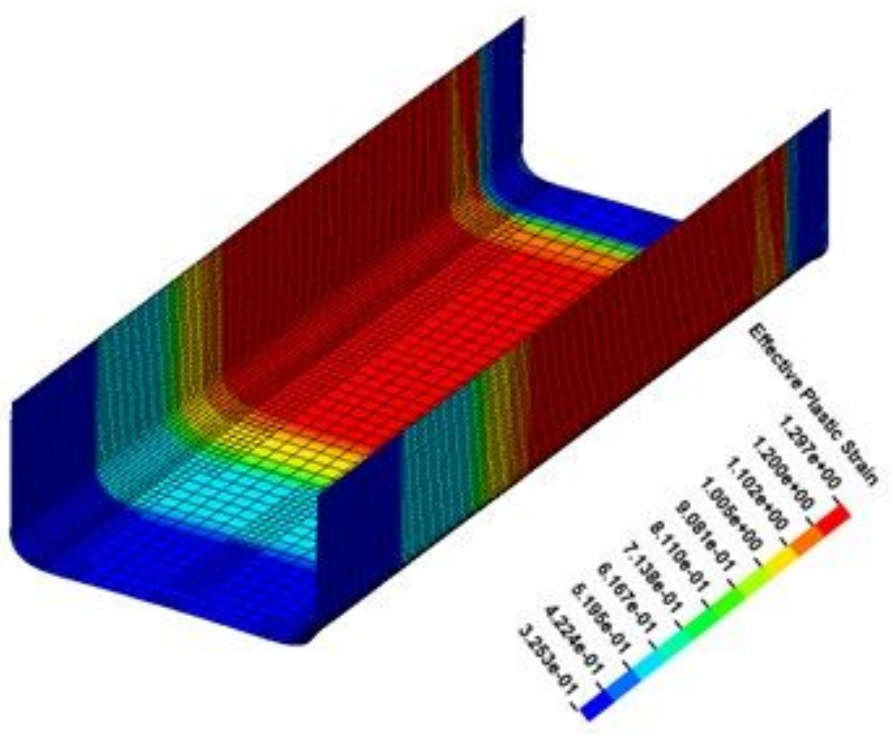

Figure 12

Effective plastic strain distribution of the workpiece after trimming
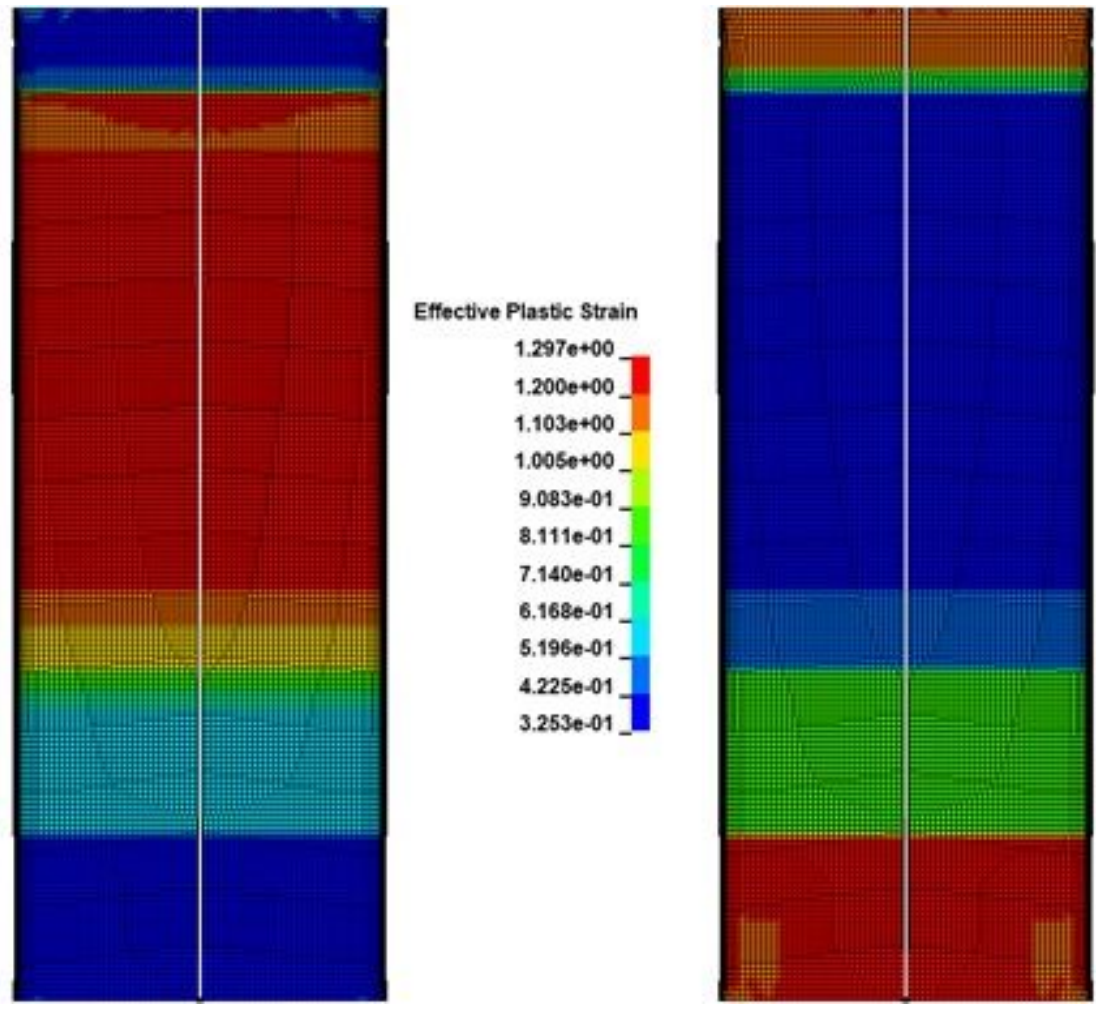

Shell Thickness

$2.4206 * 00$

$2.272 e+00$

$2.124 \mathrm{e} \div 00$

$1.977 \mathrm{e}+00$

$1.8290+00$

$1.681 \mathrm{e}+00$

$1.533 e+00$

$1.3850+00$

$1.237 e+00$

$1.0890+00$

9.411e-01_

\section{Figure 13}

The thickness and the residual plastic strain distribution of the TWST 

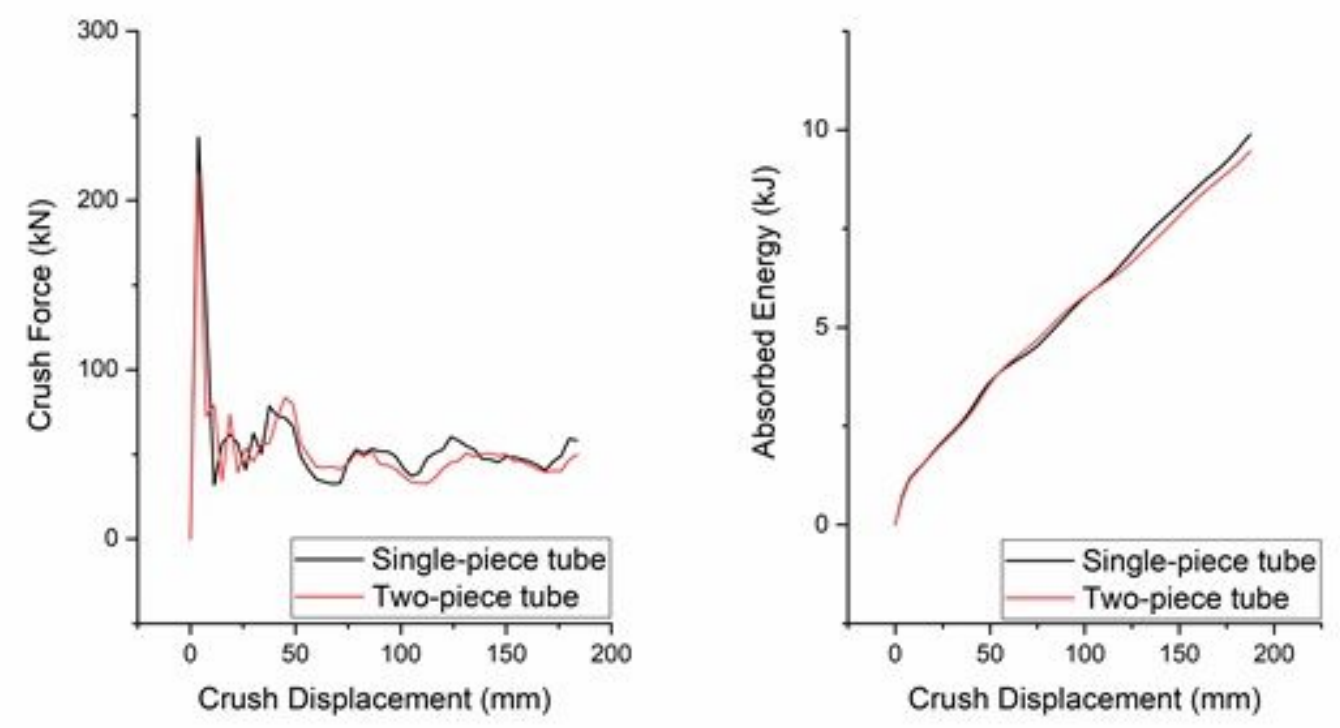

\section{Figure 14}

Plastic forming effect only on the crashworthiness performance of TWST with constant thickness of 1.5 $\mathrm{mm}$
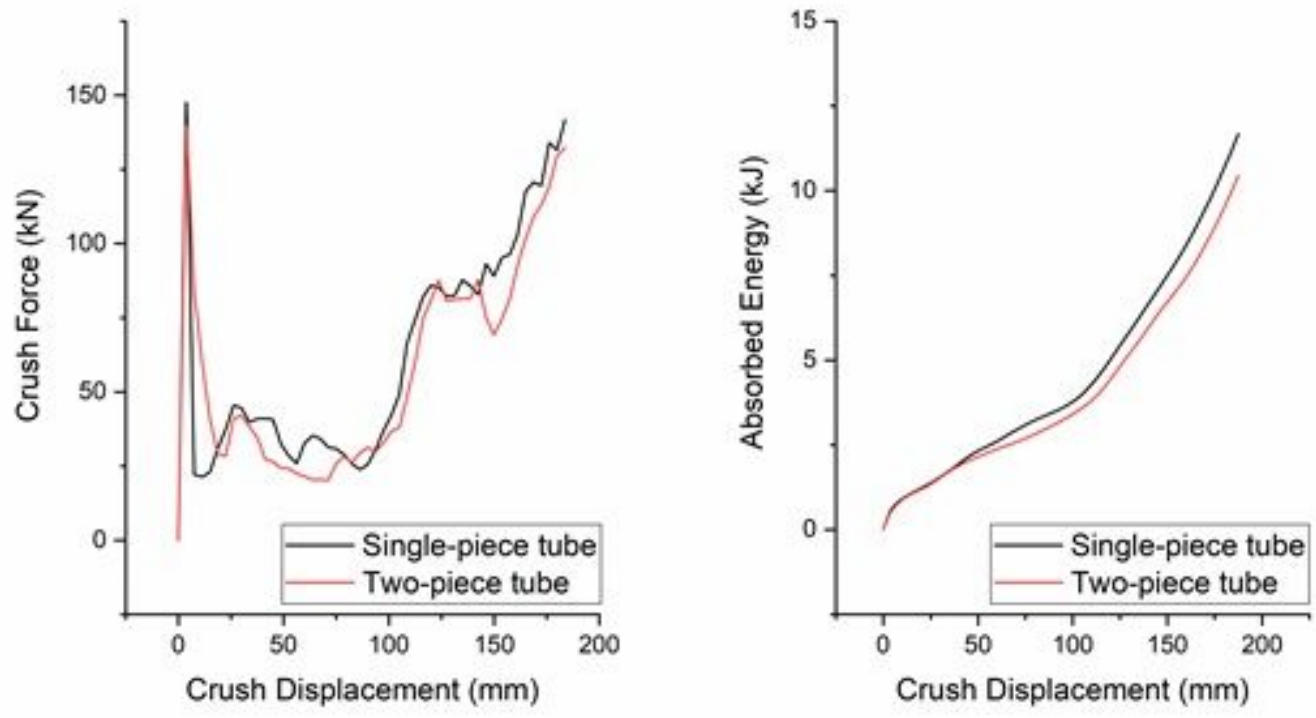

Figure 15

Optimization effect only on the crashworthiness performance of TWST 

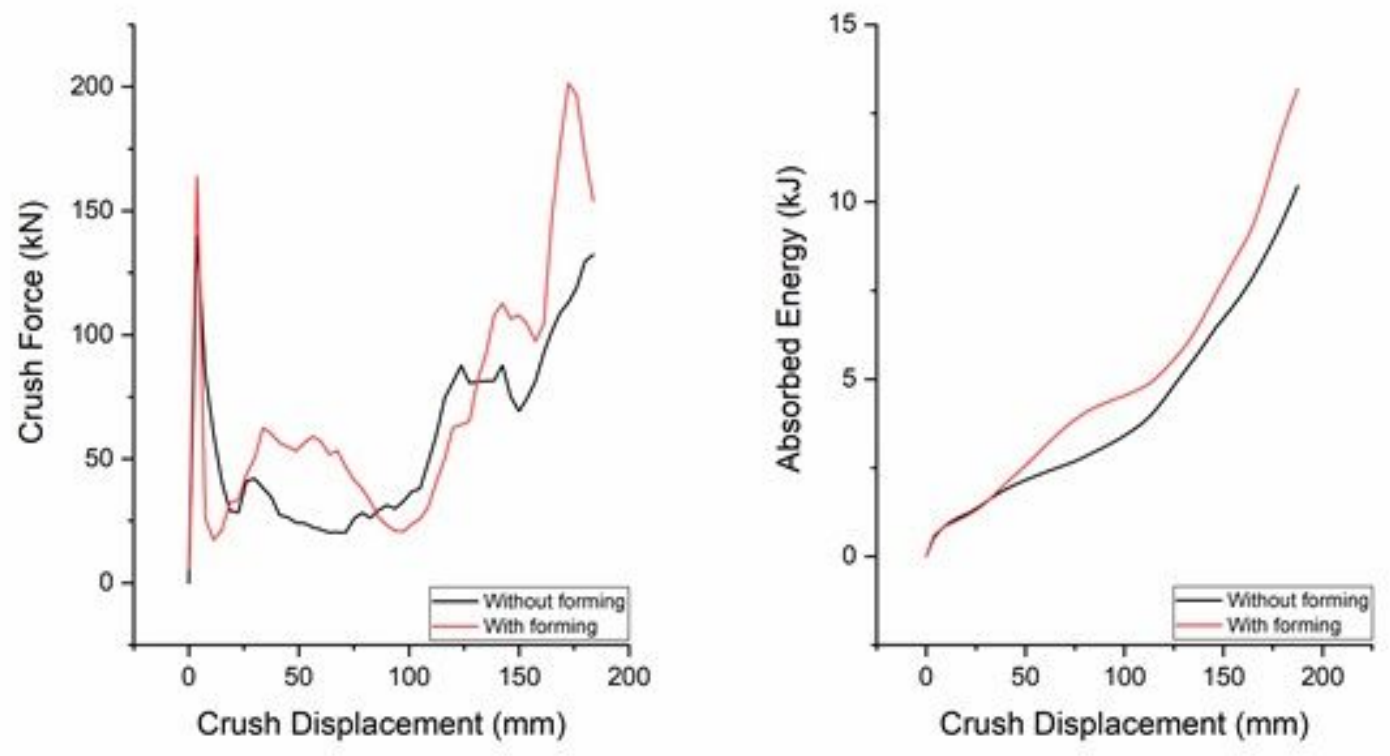

Figure 16

Effect of plastic forming on TWST with optimized thickness
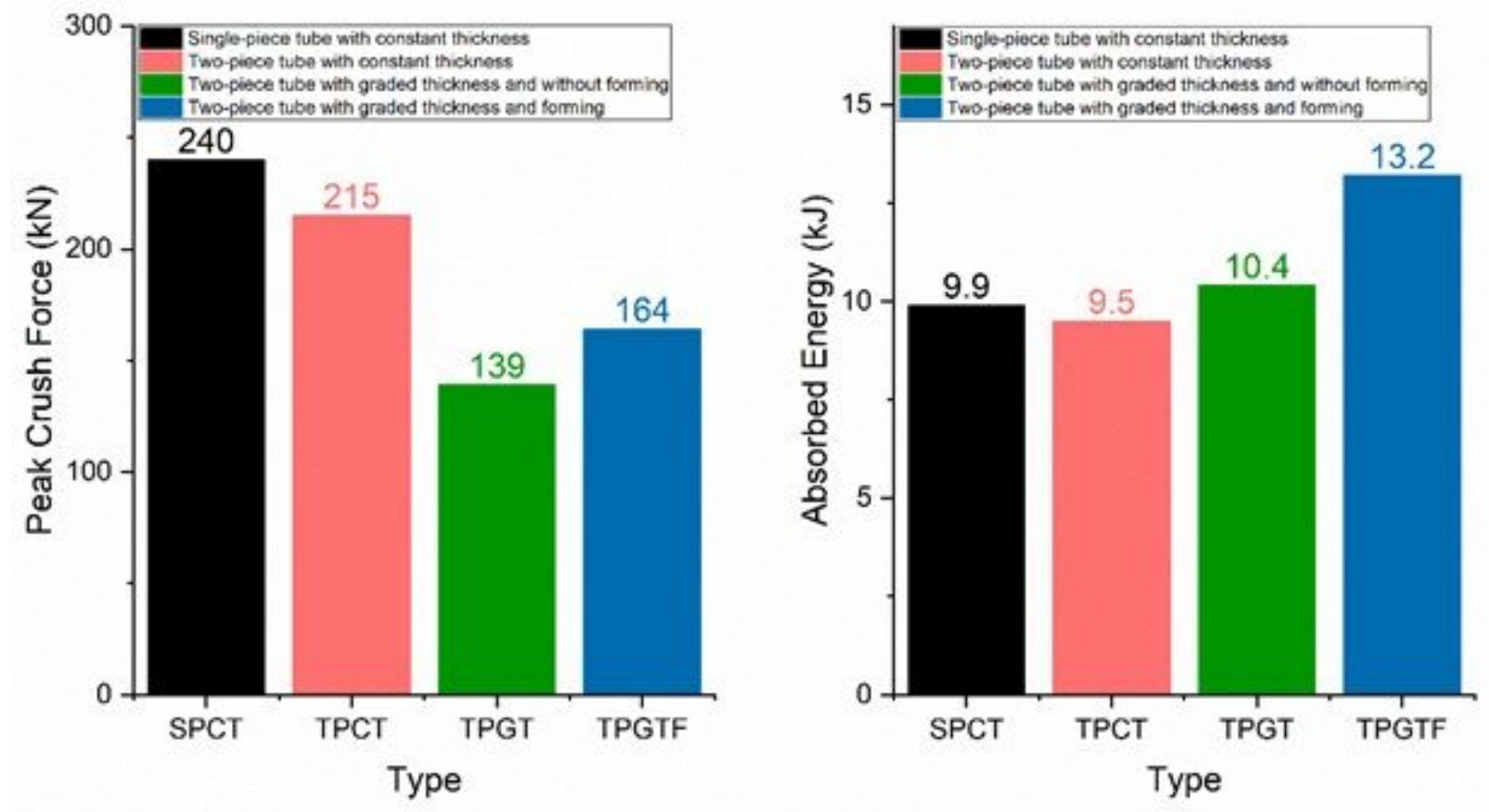

Figure 17

Comparison for all effects 